EDITORIAL EXPRESSION OF CONCERN

\title{
Editorial Expression of Concern: Interleukin-4 enhances prostate-specific antigen expression by activation of the androgen receptor and Akt pathway
}

\author{
Soo Ok Lee, Wei Lou, Min Hou, Sergio A. Onate and Allen C. Gao \\ (c) The Author(s), under exclusive licence to Springer Nature Limited 2021
}

Oncogene (2021) 40:6547; https://doi.org/10.1038/s41388-021-02034-7

Editorial Expression of Concern to: Oncogene https://doi.org/ 10.1038/sj.onc. 1206735

The Editors-in-Chief are issuing an Expression of Concern for this article [1] due to concerns about the images. The specific concerns are as follows:

- For Fig. 6C, the far-right lane in the "Nuclear $A R^{\prime}$ panel is remarkably similar to the left-most lane in the "Total AR" panel.

- Despite representing different cell lines, lanes 2-5 in the R1881/PSA panel of Fig. 1B look similar to lanes 1-4 in the PSA panel of Fig. 4A of DeMiguel et al. [2].

- Additionally, lanes 1-4 in GAPDH panel of Fig. 1B appear to overlap with lanes 1-4 in the GAPDH panel of Fig. 4A of DeMiguel et al. [2] and lanes 1-4 in the GAPDH panel of Fig. $2 \mathrm{~A}$ of Lee et al. [3].

- Figure $6 \mathrm{~B}$, which is supposed to show the results of the supershift assay of LNCaP cells after R1881 treatment, exhibits remarkable similarities with Fig. 3B from Lee et al. [3], which is supposed to show the results of the supershift assay of LN-17 cells using anti-AR antibody.

The original images are no longer available, so readers are advised to interpret the findings related to these figures with caution.
Authors Allen C. Gao and Sergio A. Onate do not agree to this Editorial Expression of Concern. Soo Ok Lee, Wei Lou, and Min Hou have not responded to any correspondence from the Publisher about this Editorial Expression of Concern.

The original article can be found online at https://doi.org/10.1038/ sj.onc. 1206735

\section{REFERENCES}

1. Lee SO, Lou W, Hou M, Onate SA, Gao AC. Interleukin-4 enhances prostate-specific antigen expression by activation of the androgen receptor and Akt pathway. Oncogene. 2003;22:7981-8. https://doi.org/10.1038/sj.onc.1206735.

2. DeMiguel F, Lee SO, Lou W, Xiao X, Pflug BR, Nelson JB, et al. Stat3 enhances the growth of LNCaP human prostate cancer cells in intact and castrated male nude mice. Prostate. 2002;52:123-9.

3. Lee SO, Lou W, Hou M, de Miguel F, Gerber L, Gao AC. Interleukin-6 promotes androgen-independent growth in LNCaP human prostate cancer cells. Clin Cancer Res. 2003;9:370-6.

\section{ADDITIONAL INFORMATION}

Correspondence and requests for materials should be addressed to Allen C. Gao.

Reprints and permission information is available at http://www.nature.com/ reprints 